\title{
Specific impulse and absolute chemical hardness
}

\author{
George Santos Marinho, Robson Fernandes de Farias* \\ Universidade Federal do Rio Grande do Norte, Cx. Postal 1524, \\ 59078-970, Natal-RN. robdefarias@yahoo.com.br
}

\begin{abstract}
The present work is dedicated to show that there are relationships between the absolute chemical hardness (n) of monopropellants and their specific impulse $\left(I_{s}\right)$. A total of sixteen monopropellants have been modelled and the absolute hardness obtained by quantum chemical calculations. The following equation was obtained: $\mathrm{I}_{\mathrm{s}}=17.562 \mathrm{\eta}+$ 125.551, providing specific impulse results in very good agreement with reference values.
\end{abstract}

Keywords: Specific impulse, absolute hardness, empirical equations, semi-empirical. 


\section{Introduction}

As is well known, the blend of a solid propellant is chosen by simultaneous considerations of processability, acceptable mechanical strength of cured propellant, and possible maximum specific impulse [1]. Specific impulse $\left(I_{s}\right)$ is, of course, a paramount parameter in order to evaluate the performance of a given propellant. Due to its importance, be able to predict the value of $I_{s}$ for a given propellant is a great advantage in aerospace research. The specific impulse rigorously defines the amount of useful energy which may be obtained from the combustion and expansion of a fuel and oxidizer. In addition to its thermodynamic significance, specific impulse also possesses an inherent ballistic importance [2].

Taking into account its maximum importance, empirical equations have been derived to allow the calculation of $I_{S}$ based on the propellant's chemical composition [3]

The molecular hardness $\eta$ and electronegativity $\chi$ are defined from formal density functional theory. Electronegativity is formally defined as $(\partial \mathrm{E} / \partial \mathrm{N})_{\mathrm{V}}$ and hardness as $1 / 2\left(\partial^{2} \mathrm{E} / \partial \mathrm{N}^{2}\right)_{\mathrm{V}}$ where $\mathrm{E}$ is the energy, $\mathrm{N}$ is the number of particles, and $\mathrm{V}$ is the potential due to the nuclei. The $\chi$ of a molecule can be defined as the average of its (first) ionization potential (IP) and its electron affinity (EA), i.e. $\chi=(\mathrm{IP}+\mathrm{EA}) / 2$. By using a DFT variation for Koopmans' theorem $(\mathrm{KT})$, we can obtain $\chi=-\left(\mathrm{E}_{\mathrm{HOMO}}+\right.$

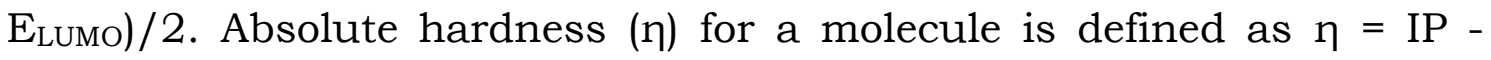
$\mathrm{EA} / 2$ and we can use $\mathrm{KT}$ to obtain $\eta=\left(\mathrm{E}_{\mathrm{LUMO}}-\mathrm{E}_{\mathrm{HOMO}}\right) / 2$.

Chemical hardness is a key parameter in order to rationalize and predict chemical and physical properties of elements and compounds. It has been shown, for example, that chemical hardness is very closely related with absolute ion hydration enthalpies [4] and with the physical properties of superheavy elements [5].

The present work is dedicated to show that there are

relationships between the absolute chemical hardness of monopropellants and their specific impulse. 


\section{Methodology}

The quantum chemical calculations were performed by using Spartan [6]. Specifically, the thermochemical parameters ( $E_{\text {HOMO }}, E_{\text {LUMO }}$ and $\Delta \mathrm{H}_{\mathrm{f}}(\mathrm{g})$ ) were calculated by using the $\mathrm{T} 1$ recipe.

The $\mathrm{T} 1$ recipe reproduces $\mathrm{G} 3(\mathrm{MP} 2)$ heats of formation (but at significantly reduced computation cost) with a mean absolute error of $<1 \mathrm{~kJ} / \mathrm{mol}$. [7]. T1 substitutes the MP2/6-31G* geometry used in G3(MP2) by a HF/6-31G* geometry, eliminates both the HF/6-31G* frequency and the $\mathrm{QCISD}(\mathrm{T}) / 6-31 \mathrm{G}^{*}$ energy calculations and approximates the MP2 energy calculation with the G3MP2 large basis set by an analogous calculation using dual basis set RI-MP2 techniques. Taken together, these changes reduce computation time by 2-3 orders of magnitude, and T1 calculations on molecules in the molecular weight range of 400-500 amu are practical. It reproduces the full set of $\sim 2,000$ experimental heats of formation in the NIST thermochemical database with a mean absolute error of $9 \mathrm{~kJ} / \mathrm{mol}$. [7].

For comparison, $\mathrm{E}_{\mathrm{HOMO}}$ and $\mathrm{E}_{\mathrm{LUMO}}$ energies were also calculated by using Hartree-Fock $\left(6-311+\mathrm{G}^{* *}\right)$ approach and no significant difference was observed to $\mathrm{T} 1$ values. Hence, all calculated thermochemical data shown in Table 1, are those obtained by using T1 thermochemical recipe.

Dany Frem [4], have derived two empirical equations that in order to predict the specific impulse of more than 165 compositions belonging to virtually all classes of propellants such as monopropellants, singlebase, double-base, triple-base, and cast modified double-base (CMDB) propellants, pseudo-propellants, composite propellants, liquid monoand bipropellants, and finally hybrid propellants. The obtained and tested empirical equations were really reliable, providing results in very good agreement with literature data. The obtained equation [3] is: 


$$
I_{\mathrm{s}}\left(\mathrm{Nsg}^{-1}\right)=\left(-4.459+121.81 \mathrm{~N}_{\mathrm{g}}+4.697 \mathrm{Q}\right)^{1 / 2}
$$

where $(Q)$ and $(N g)$, are the heat of reaction in $\left(\mathrm{kcal} \mathrm{g}^{-1}\right)$ and the number of moles of gaseous reaction products per gram of propellant, respectively, were calculated according to:

$$
\begin{gathered}
\mathrm{Q}=\left[28.9 \mathrm{~b}+47[\mathrm{~d}-(\mathrm{b} / 2)]+\Delta \mathrm{H}_{\mathrm{f}}{ }^{0}\right] / \mathrm{M}_{\mathrm{w}} \\
\mathrm{N}_{\mathrm{g}}=(2 \mathrm{c}+2 \mathrm{~d}+\mathrm{b}) /(48 \mathrm{a}+4 \mathrm{~b}+56 \mathrm{c}+64 \mathrm{~d})
\end{gathered}
$$

where: $a, b, c$ and $d$ are the number of carbon $(\mathrm{C})$, hydrogen $(\mathrm{H})$, nitrogen $(\mathrm{N})$ and oxygen $(\mathrm{O})$ atoms in the propellant composition, $\left(\Delta \mathrm{H}_{\mathrm{f}}{ }^{\mathrm{O}}\right.$ kcal $\mathrm{mol}^{-1}$ ) represents the condensed phase heat of formation, and $M w$ is the composition's molecular weight.

The $I_{s}$ values calculated using Eq. (1) are employed as reference values in the present work (Table 1), since they agree very well with those calculated by using ISPBKW code [3] but employ simple empirical data (number of atoms), as well as experimental $\Delta \mathrm{H}_{\mathrm{f}}{ }^{0}$ values. Hence, they came from the propellant itself, with none especial or postulated theoretical assumption.

In order to shown the relationships between the absolute chemical hardness of monopropellants and their specific impulse, seven monopropellants were modelled: 2,4,6-trinitrotoluene (TNT), 1,3,5Trinitro-1,3,5-triazinane (RDX), 1,3,5,7-Tetranitro-1,3,5,7-tetrazoctane (HMX), Propane-1,2,3-triyl trinitrate (nitroglycerin, NG), 2,2Bis[(nitrooxy)methyl]propane-1,3-diyl dinitrate (PETN), nitromethane (NM) and 1,3,5-Trinitro-2-[2-(2,4,6-trinitrophenyl)ethenyl]benzene (hexanitrostilbene, HNS).

In order to verify the reliability of the proposed relationships, a new set of monopropellants were modelled (Figure 2): 2, $2^{\prime}, 4,4^{\prime}, 6,6^{-}$ hexanitroazobenzene (HNAB), 1-nitroguanidine (NQ), diazodinitrophenol 
(DDNP), 1,3,5-Triamino-2,4,6,-trinitrobenzene (TATB), Picric acid (PA), 2,4,6-Trinitrophenylmethylnitramine (Tetryl), Diethanolnitramine dinitrate (DINA), Ethriol trinitrate (ETN), and Ethylenedinitramine (EDNA).

Results and discussion

The obtained results are summarized in Tables 1-3. The combustion enthalpy values are those provided by NIST [8]. The specific impulse values are those calculated using Eq. (1) [3].

As can be seen from Table 1 data, the investigated monopropellants have different chemical formulas and molar masses, as well as combustion enthalpies (a parameter directly related with the pressure and temperature in the combustion chamber, and hence, with specific impulse), with NM and HNS as the opposite extremes and TNT occupying an intermediary position. So, a very simplistic reasoning based only on the number of carbon atoms per formula, molar masses and combustion enthalpies could not explain the relatively close $I_{S}$ values for such monopropellants. However, as can also be verified in the

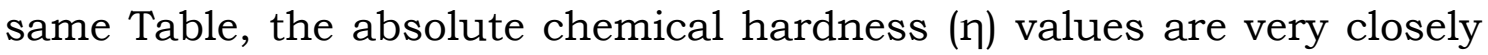
related.

As is well known, $\eta$ values are related with polarizability (harder chemical species are less polarizable), and with, of course, $\mathrm{E}_{\mathrm{HOMO}}$ and E $_{\text {LUMO }}$ energies. That is, approximately (Koopman's theorem) with ionization energies and electron affinities of such species. In other words, with their chemical reactivity and the possibility of to form lighter or heavier gaseous products (lighter gaseous products favours higher $I_{s}$ values). So, it is not so surprisingly that a closer relationship between $\eta$ and $I_{s}$ values can be verified.

In Figure 3, the monopropellants $I_{s}$ values (Eq. 1) are plotted as a function of $\eta$. As can be seen, a linear relationship ( $r=0.9508)$ is obtained, providing the empirical equation: 


$$
I_{s}=17.562 \eta+125.551
$$

whose sell-consistency was verified (Table 2).

Furthermore, in order to verify the reliability of Eq. 4, it was applied to another set of monopropellants (Table 3), with good results, as can be verified.

\section{References}

[1] Krishnan S, Raghavan, J. 2020. Chemical Rockets - Performance Prediction and Internal Ballistics Design, Springer, New York.

[2] Mader, C.L. 2008. Numerical modeling of explosives and propellants, CRC Press, Boca Raton.

[3] Frem, D., 2018. A Reliable Method for Predicting the Specific Impulse of Chemical Propellants, J. Aerosp. Technol. Manag. 10: e 3318. doi: 10.5028/jatm.v10.945.

[4] Kaya, S., de Farias, R.F., 2018. Absolute ion hydration enthalpies from absolute hardness and some VBT Relationships, Chem. Phys. Lett., 691: 169-171.

[5] de Farias, R.F. 2018. The first and second ionization energies of the element 119: absolute hardness and Mulliken electronegativity for the cation $119^{+}$based on an empirical equation involving absolute hardness, Mendeleev Commun., 28: 306-307

[6] Wavefunction Inc., Irvine, California, USA.

[7] Sparan`16 Tutorial and user's guide, Wavefunction Inc., Irvine, California, USA.

[8] National Institute of Standards and Technology (https://www.nist.gov/). 
Table 1. Calculated thermochemical data for selected monopropellants.

\begin{tabular}{|c|c|c|c|c|c|c|c|c|}
\hline Propellant & Formula & $\begin{array}{c}\text { Molar } \\
\text { mass /gmol-1 }\end{array}$ & $\begin{array}{c}\text { Ehomo }_{\text {hom }} \\
/ \mathrm{eV}\end{array}$ & $\begin{array}{l}\text { Elumo } \\
/ \mathrm{eV}\end{array}$ & $\begin{array}{l}\eta \\
/ \mathrm{eV}\end{array}$ & $\begin{array}{c}\Delta \mathrm{H}_{\mathrm{f}(\mathrm{g})} \\
/ \mathrm{kJmol}^{-1}\end{array}$ & $\begin{array}{c}\Delta_{\mathrm{c}} \mathrm{H}_{(\mathrm{s}, 1)} \\
/ \mathrm{kJmol}^{-1}\end{array}$ & $\mathrm{I}_{\mathrm{S}} / \mathrm{s}^{\#}$ \\
\hline TNT & $\mathrm{C}_{7} \mathrm{H}_{5} \mathrm{~N}_{3} \mathrm{O}_{6}$ & 227.13 & -11.50 & 0.30 & 5.90 & $\begin{array}{c}56.64 \\
(24.1 \pm 3.5)^{*}\end{array}$ & $(-3410 . \pm 20)^{*}$ & 221.20 \\
\hline RDX & $\mathrm{C}_{3} \mathrm{H}_{6} \mathrm{~N}_{6} \mathrm{O}_{6}$ & 222.08 & -12.52 & 2.33 & 7.43 & $\begin{array}{l}234.63 \\
(192)^{*}\end{array}$ & $\left(-2120^{-} \pm 5.0\right)^{*}$ & 261.98 \\
\hline HMX & $\mathrm{C}_{4} \mathrm{H}_{8} \mathrm{~N}_{8} \mathrm{O}_{8}$ & 296.16 & -12.46 & 2.18 & 7.32 & $\begin{array}{c}262.12 \\
(264.9)^{* 1}\end{array}$ & $\left(-2820^{-} \pm 2.8\right)^{*}$ & 261.98 \\
\hline $\mathrm{NG}$ & $\mathrm{C}_{3} \mathrm{H}_{5} \mathrm{~N}_{3} \mathrm{O}_{9}$ & 227.09 & -13.48 & 2.72 & 8.10 & $\begin{array}{c}-273.17 \\
(-279.1 \pm 2.7)^{*}\end{array}$ & $\left(-1529^{-} \pm 10\right)^{*}$ & 268.10 \\
\hline PETN & $\mathrm{C}_{5} \mathrm{H}_{8} \mathrm{~N}_{4} \mathrm{O}_{12}$ & 316.14 & -13.55 & 2.53 & 8.04 & -385.09 & $(-2572 . \overline{4} \pm 0.8)^{*}$ & 259.94 \\
\hline NM & $\mathrm{CH}_{3} \mathrm{NO}_{2}$ & 61.04 & -12.35 & 3.13 & 7.74 & $\begin{array}{c}-66.34 \\
(-81 \pm 1)^{*}\end{array}$ & $(-709.6 \pm 0.4)^{*}$ & 258.92 \\
\hline HNS & $\mathrm{C}_{14} \mathrm{H}_{6} \mathrm{~N}_{6} \mathrm{O}_{12}$ & 450.23 & -11.12 & -0.36 & 5.38 & $\begin{array}{l}264.75 \\
(238.4)^{*}\end{array}$ & $(-6434 . \overline{2} \pm 5.0)^{*}$ & 223.24 \\
\hline
\end{tabular}

${ }^{*}$ Reference values (Ref. 8); \#Calculated using Eq. (1) (Ref. 3). ${ }^{1} \mathrm{U} \operatorname{sing} \Delta \mathrm{H}_{\mathrm{f}}(\mathrm{s})+\Delta \mathrm{H}_{\mathrm{sub}}=103+161.9$ (both from Ref. 7); 
Table 2. Self-consistence test to Eq. (4). Percentage deviations in parentheses.

\begin{tabular}{|l|c|c|}
\hline Propellant & $\mathrm{I}_{\mathrm{s}} / \mathrm{s}^{\#}$ & $\mathrm{I}_{\mathrm{s}} / \mathrm{s}(\mathrm{Eq} .4)$ \\
\hline TNT & 221.20 & $229.17(+3.6 \%)$ \\
\hline RDX & 261.98 & $256.04(-2.3 \%)$ \\
\hline HMX & 261.98 & $254.10(-3.0 \%)$ \\
\hline NG & 268.10 & $267.80(-0.1 \%)$ \\
\hline PETN & 259.94 & $266.75(+2.6 \%)$ \\
\hline NM & 258.92 & $261.48(+1.0 \%)$ \\
\hline HNS & 223.24 & $220.03(-1.4 \%)$ \\
\hline
\end{tabular}

\#Calculated using Eq. (1) (Ref. 3). 
Table 3. Specific impulse to some selected monopropellants, calculated by using Eq. (4). Percentage deviations in parentheses.

\begin{tabular}{|l|c|c|c|c|c|}
\hline Propellant & $\begin{array}{c}\mathrm{E}_{\text {homo }} \\
/ \mathrm{eV}\end{array}$ & $\begin{array}{c}\mathrm{E}_{\text {lumo }} \\
/ \mathrm{eV}\end{array}$ & $\begin{array}{c}\eta \\
/ \mathrm{eV}\end{array}$ & $\mathrm{I}_{\mathrm{s}} / \mathrm{s}^{\#}$ & $\mathrm{I}_{\mathrm{s}} / \mathrm{s}$ (Eq.4) \\
\hline HNAB & -11.82 & -0.09 & 5.87 & 234.45 & $228.64(-2.5 \%)$ \\
\hline NQ & -10.98 & 3.13 & 7.06 & 215.09 & $249.54(+16.0)$ \\
\hline DDNP & -9.75 & -0.04 & 4.86 & 227.32 & $210.73(-7.3 \%)$ \\
\hline TATB & -9.88 & 1.54 & 5.71 & 206.93 & $225.83(+7.2 \%)$ \\
\hline PA & -11.12 & 0.07 & 5.60 & 219.16 & $223.81(+2.1)$ \\
\hline Tetryl & -12.06 & -0.31 & 5.88 & 239.55 & $228.82(-4.5 \%)$ \\
\hline DINA & -11.78 & 3.02 & 7.40 & 259.94 & $255.51(-1.7 \%)$ \\
\hline ETN & -12.94 & 3.22 & 8.08 & 247.71 & $267.45(+8.0 \%)$ \\
\hline EDNA & -12.33 & 3.97 & 8.15 & 252.80 & $268.68(+6.3 \%)$ \\
\hline
\end{tabular}

\#Calculated using Eq. (1) (Ref. 3). 
<smiles>Cc1c([N+](=O)[O-])cc([N+](=O)[O-])cc1[N+](=O)[O-]</smiles>

(a)<smiles>O=[N+]([O-])OCC(CO[N+](=O)[O-])O[N+](=O)[O-]</smiles>

(d)<smiles>CC([O-])[O-]</smiles>

(f)<smiles>O=[N+]([O-])N1CN([N+](=O)[O-])CN([N+](=O)[O-])C1</smiles>

(b)<smiles>O=[N+]([O-])N1CN([N+](=O)[O-])CN([N+](=O)O)CN([N+](=O)[O-])C1</smiles>

(c)<smiles>O=[N+]([O-])OCC(CO[N+](=O)[O-])(CO[N+](=O)[O-])CO[N+](=O)[O-]</smiles>

(e)

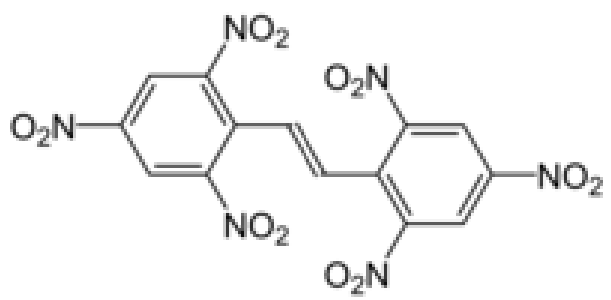

(g)

Figure 1. The modelled monopropellants (to obtain Eq. 4): (a) TNT, (b) RDX, (c) HMX, (d) NG, (e) PETN, (f) NM and (g) HNS. 
<smiles>O=[N+]([O-])c1cc([N+](=O)[O-])c(N=Nc2c([N+](=O)[O-])cc([NH+]([O-])O)cc2[N+](=O)[O-])c([N+](=O)[O-])c1</smiles>

(a)<smiles>Nc1c([N+](=O)[O-])c(N)c([N+](=O)[O-])c(N)c1[N+](=O)[O-]</smiles>

(d)<smiles>NC(N)=N[N+](=O)[O-]</smiles>

(b)<smiles>O=[N+]([O-])c1cc([N+](=O)[O-])c(O)c([N+](=O)[O-])c1</smiles>

(e)<smiles>N=C1C=C([N+](=O)[O-])C=C([N+](=O)[O-])C1=O</smiles>

(c)<smiles>CN(c1c([N+](=O)[O-])cc([N+](=O)[O-])cc1[N+](=O)[O-])[N+](=O)[O-]</smiles>

(f)<smiles>O=[N+]([O-])OCCN(CCO[N+](=O)[O-])[N+](=O)[O-]</smiles>

(g)

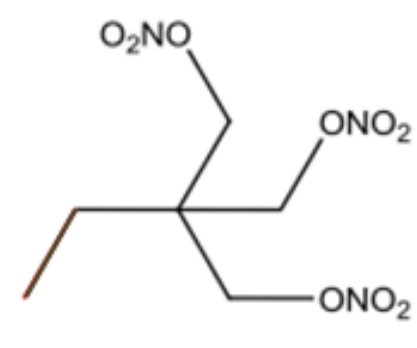

(h)<smiles>O=[N+]([O-])NCCN[N+](=O)[O-]</smiles>

(i)

Figure 2. Modelled monopropellants to test Eq. (4) reliability: (a) HNAB, (b) NQ, (c) DDNP, (d) TATB, (e) PA, (f) Tetryl, (g) DINA, (h) ETN and (i) EDNA. 


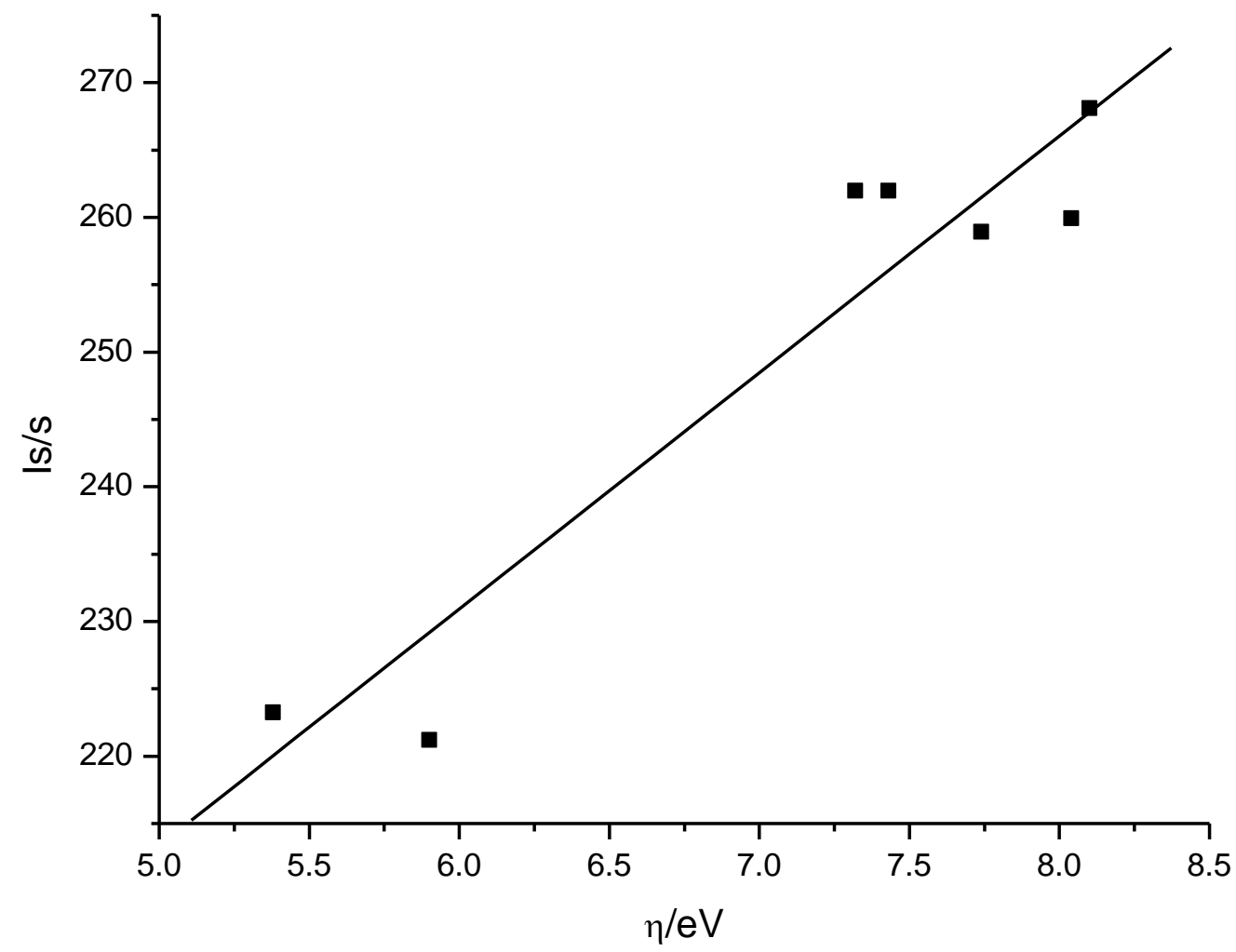

Figure 3. $I_{s}$ (Eq. 1) as a function of $\eta$ for Table 1 monopropellants. 